\title{
ORDEM, ESTRATÉGIAS DE FOCALIZAÇÃO, PREENCHIMENTO LEXICAL DA POSIÇÃO DO SUJEITO E RITMO EM PORTUGUÊS EUROPEU EEM PORTUGUÊS BRASILEIRO*
}

Order, focus strategies, lexical filling of subject position in European Portuguese and Brazilian Portuguese

Flaviane Romani Fernandes**

\section{Introdução}

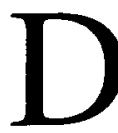
e acordo com Chomsky (1985), a Língua-E é definida como "a totalidade dos enunciados que podem ser produzidos numa comunidade de fala"; já a Língua-I é um objeto mental, o saber que as pessoas têm da língua e que lhes permite falar e entender essa língua.

Galves (1998), baseada na distinção Língua-Externa (Língua-E) / LínguaInterna (Língua-I) proposta por Chomsky (1985), afirma que do ponto de vista da Língua-I, ou seja, da gramática, o português europeu (doravante PE) e o português brasileiro (doravante $\mathrm{PB}$ ) são duas línguas diferentes.

A afirmação feita por Galves (1998) é corroborada por ocorrências peculiares na sintaxe de PB que, se presentes em PE, produziriam enunciados agramaticais nesta variedade. Ou, pelo fato de que, em alguns casos, apesar de os enunciados serem superficialmente comuns às duas variedades, não recebem a mesma interpretação. A autora aponta as seguintes ocorrências gramaticais próprias de PB:

* Este trabalho é fruto do desenvolvimento da pesquisa de mestrado $O$ papel do rimo nas escolhas léxico-sintáticas em pormuguês europeu e em português brasileiro. Esta pesquisa de mestrado foi desenvolvida com o apoio da Fapesp (processo 01/11285-9) e está inserida no âmbito do projeto temático, também financiado pela Fapesp (processo 98/3382-0), Padröes rítmicos, fixasão de parâmetros e mudansa lingïistica.

** Doutoranda do Programa de Pós-graduação em Linguística da UNICAMP. 
FERNANDES, F. R. Ordem, estratégias de focalizaçāo, preenchimento...

1. A gramática brasileira substitui o clítico acusativo de terceira pessoa pelo pronome tônico e por uma categoria vazia de natureza pronominal. Ex.1: Vi ele ontem na rua. Ex. 2: (falando dos pastéis) O rapaz QUE TROUXE da pastelaria era o teu afilhado.'

2. A gramática brasileira limita a posição dos clíticos à adjacência do verbo temático. Ex.: Agora não tinha ME lembrado.'

3. A gramática brasileira produz um sujeito nulo de interpretação indeterminada, que requer certos contextos para receber uma interpretação referencial específica, contrariamente ao PE ou a outras línguas de sujeito nulo. Ex.: (referindo-se a pessoa indeterminada) Não usa mais freio. ${ }^{3}$

4. A gramática brasileira produz estruturas em que um objeto assume função de sujeito sem que nenhuma marca morfológica seja necessária para legitimar essa mudança. Ex.: A balança está consertando. ${ }^{4}$

Neste trabalho não serão abordadas diferenças deste nível, ou seja, diferenças categóricas entre PB e PE como as apontadas por Galves (1998), como o fato, por exemplo, de o PE ser enclítico e o PB ser proclítico:

(1) Em PE: ...e as ovelhas seguem-no...

(2) Em PB: ...e as ovelhas o seguem...5

No presente artigo trataremos de diferenças não categóricas. Trataremos, especificamente, das diferenças quanto à ordem ocupada pelo elemento sujeito nas sentenças de PE e PB, diferenças estas que, embora na maioria dos casos resultem em enunciados possíveis nas duas variedades de português, são, seguindo Nespor e Guasti (2001), realizadas de maneira a refletir estratégias de focalização diferentes e, por hipótese, realizadas de maneira a otimizar o ritmo em cada variedade.

Este artigo será apresentado em cinco seções:

1 O exemplo apresentado em 1 é extraído de Galves (1998) e o exemplo apresentado em 2, de Raposo (1986).

2 Exemplo extraído do corpus do projeto NURC.

3 Conferir nota anterior.

4 Exemplo extraído de Galves (1998).

5 Exemplos de trechos de textos bíblicos traduzidos do grego ou aramaico respectivamente para PE e PB. 
(i) Seção 1. O princípio Focus to Stress Alignment (FSA) e as opções escolhidas pelas línguas para satisfazê-lo - Apresentaremos, nesta seção, o princípio Focus to Stress Alignment de Jackendoff (1972) e, à luz da proposta de Nespor e Guasti (2001), apresentaremos as estratégias escolhidas pelas línguas para satisfação deste mesmo princípio;

(ii) Seção 2. As opções escolhidas por PE e PB para satisfazer o princípio FSA - Nesta seção apresentaremos as opções escolhidas por PB e por PE na satisfação do princípio FSA já referido;

(iii) Seção 3. Corpora e metodologia - Já nesta seção 3 faremos uma breve apresentação dos corpora dos quais foram extraídos enunciados para a comparação de PB e PE em nossa pesquisa e também apresentaremos a metodologia utilizada em nossa análise de dados;

(iv) Seção 4. Apresentação de dados e discussão - Por sua vez, nesta seção 4, apresentaremos quatro enunciados (respectivamente dois de $\mathrm{PE}$ e dois de $\mathrm{PB}$ ) que, embora apresentem a mesma estrutura informacional subjacente, apresentam diferenças, entre PE e PB, em relação à posição que o elemento sujeito ocupa nas sentenças. $A$ seguir é apresentada uma hipótese, baseada na proposta de Nespor e Guasti (2001) e em questões rítmicas, para a explicação dessas diferenças em relação à ordem ocupada pelos elementos nas sentenças de PE e PB;

(v) Seção 5. Considerações finais - Por fim, tentaremos mostrar que, além da fixação do parâmetro sintático ( \pm pro), como afirmam Nespor e Guasti (2001), questões de outra natureza, por hipótese, questōes de natureza rítmica, podem também estar envolvidas nas diferentes estratégias de focalização escolhidas pelas línguas com a finalidade de satisfazer o princípio FSA de Jackendoff (1972).

\section{O principio Focus to Stress Alignment (FSA) e as opções escolhidas pelas línguas para satisfazê-lo}

Conforme o princípio Focus to Stress Alignment (FSA) de Jackendoff (1972), baseado em Chomsky (1971), o foco semântico e a proeminência fonológica principal da sentença devem estar alinhados: 
FERNANDES, F. R. Ordem, estratégias de focalização, preenchimento...

Focus to Stress Alignment (FSA)

If $P$ is chosen as the focus of a sentence $S$, the highest stress in $S$ will be on the syllable of $P$ that is assigned highest stress by the regular stress rule (Jackendoff, 1972, p. 237).

Isto significa que se na estrutura-S um elemento é assinalado com o traço $+F$, este elemento será interpretado como o foco da sentença na forma lógica (LF) e receberá a proeminência principal na representação fonológica (PF). No exemplo (3), apresentado logo abaixo, ao João é o foco da sentença e porta a proeminência fonológica principal desta ${ }^{6}$ pela aplicação de regras fonológicas regulares de acento ${ }^{7}$ e, portanto, satisfaz o princípio FSA.

A quem você deu um livro?

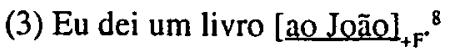

Todavia, cabe-nos indagar sobre o que aconteceria com os casos em que as línguas optam, em uma sentença, por uma tal ordem dos elementos, de maneira que o elemento focalizado não ocupe a posição receptora de proeminência fonológica principal na sentença pelas regras fonológicas regulares de acento. Como exemplo, podemos citar a sentença apresentada em (4):

O que você deu ao João?

(4) Eu dei [um livrol $]_{+F}$ ao João.

Considerando a ordem dos elementos da sentença acima e o fato de que a proeminência fonológica principal da sentença recai sempre na palavra mais à direita desta, i. e., neste caso, ao João, há um desalinhamento entre a representação fonológica e a representação sintática (onde o traço $\mathrm{F}$ é assinalado). Ou seja, o constituinte focalizado não constitui o núcleo entoacional, portanto viola o princípio FSA.

6 Neste trabalho, entendemos como elemento portador de proeminência fonológica principal da sentença aquele elemento que porta o evento tonal $\mathrm{H}$ mais proeminente em relação aos outros eventos tonais presentes na mesma sentença.

7 Pela Regra Nuclear de Acento (NSR - Nuclear Stress Rule), proposta por Chomsky e Halle (1968), o acento principal de uma sentença é assinalado automaticamente por regras fonológicas regulares, independentemente de considerações discursivas. A NSR se aplica a toda a sentença e "cegamente" assinala 0 acento no elemento mais encaixado da sentença.

8 O elemento sublinhado é o elemento focalizado e portador da proeminência fonologica principal da sentença. 
FERNANDES, F. R. Ordem, estratégias de focalização, preenchimento...

Nestes casos, as línguas, de acordo com Nespor e Guasti (2001), têm duas opções:

\begin{abstract}
A language may have at its disposal one of two mechanisms to remedy this type of misalignment: either a different Word order is chosen so that the $+F$ constituent is rightmost in its intonational phrase, or the main prominence is moved to the constituent marked $[+F]$ in the syntactic tree.
\end{abstract}

Ou seja, em nosso exemplo, para que fosse respeitado o princípio FSA, ou deveria haver a ordem Eu dei ao João um livro na representação fonológica ou deveria haver uma mudança da proeminência fonológica principal em "ao João" para "um livro".

Em uma língua como o inglês, segundo Nespor e Guasti (2001), a possibilidade de reordenar os constituintes da sentença de tal modo que o objeto direto, que carrega $+\mathrm{F}$, siga o objeto indireto não é gramatical (no mínimo com uma entoação não enfática). Exemplo:

(5) * I gave John $\underline{\text { a book. }}$

'Eu dei ao João um livro'.

Ao invés do reordenamento dos constituintes na sentença, em inglês, o princípio FSA é satisfeito pelo movimento da proeminência principal no último constituinte (to John) da sentença para o constituinte que carrega $+\mathrm{F}$ (a book), e neste caso, o objeto direto permanece in situ:

(6) I gave a book to John.

'Eu dei um livro ao João'.

Já em italiano, também conforme Nespor e Guasti (2001), a opção de mover a proeminência principal da sentença para o constituinte $+\mathrm{F}$ (em contextos não contrastivos) produz sentenças agramaticais:

(7) *Giacomo ha dato un libro a Tommaso. ${ }^{9}$

'Giacomo deu um livro ao Tommaso'

9 Exemplo retirado de Nespor e Guasti (2001). 
FERNANDES, F. R. Ordem, estratégias de focalização, preenchimento...

Em italiano, a opção escolhida para satisfazer o princípio FSA é o reordenamento dos constituintes na sentença:

(8) Giacomo ha dato a Tommaso un libro. ${ }^{10}$

'Giacomo deu ao Tommaso um livro'.

De acordo com Nespor e Guasti (2001), acrescenta-se que línguas como o francês (no caso de sentenças em que há dativo), o espanhol (cf. também Zubizarreta, 1998) e o grego, para satisfazerem o princípio FSA, comportam-se como o italiano, enquanto línguas como o alemão comportam-se como o inglês.

Nespor e Guasti (2001) postulam que os diferentes mecanismos utilizados por línguas como o inglês e o italiano para o alinhamento foco/proeminência são a consequiência da fixação diferente do parâmetro sintático $( \pm$ pro). Ou seja, línguas pro-drop escolheriam a primeira opção apresentada pelas mesmas autoras na satisfação do princípio FSA, enquanto línguas não pro-drop escolheriam a segunda opção na satisfação do mesmo princípio.

Nespor e Guasti (2001), seguindo Belletti e Shlonsky (1995), propõem que a possibilidade de haver ordens diferentes para a posição dos objetos direto e indireto (ou outros complementos) nas sentenças em línguas pro-drop como o italiano decorre da existência, nesta língua, de um pronome foneticamente vazio com a função de objeto (ou sujeito), comumente chamado pro. Línguas como o italiano, o francês, o espanhol e o grego permitem a existência do pronome pro, como pode ser comprovado pelo exemplo em italiano" dado por Nespor e Guasti (2001):

(9) Lo Yoga mantiene pro in forma.

'O Yoga mantém em forma'.

Já em inglês o pronome pro não é permitido, como pode ser visto pela agramaticalidade da tradução de (9) dada em (10a). (10a) só se torna gramatical se um pronome foneticamente realizado substitui pro, como as já referidas autoras mostram em (10b):

(10) a. * Yoga keeps healthy.

b. Yoga keeps one healthy.

10 Conferir a nota imediatamente anterior.

11 Exemplos semelhantes também são encontrados nas outras línguas citadas. 
Nespor e Guasti (2001) presumem (conforme Stowell, 1981; Costa, 1998; Neeleman; Reinhart, 1998) que a adjacência do verbo e do objeto direto é requerida para a atribuição de caso no exemplo (10b). Se a ordem de uma sentença é V NP PP, a adjacência é respeitada, tanto em italiano como em inglês. Porém, quando a ordem é V PP NP, o NP (objeto) não está adjacente ao verbo. Dada a presença de um objeto nulo pro em italiano, a estrutura profunda da ordem V PP NP é V pro ${ }_{i}$ PP NP, portanto, satisfazendo a adjacência por meio de pro, que, por sua vez, forma uma cadeia com o objeto lexical. Assim, pro recebe caso por adjacência e o transmite para o NP lexical. Uma vez que em inglês o parâmetro de existência do pronome pro é de valor negativo e o NP (objeto) não está adjacente ao verbo (ordem V PP NP), o NP (objeto) não pode receber caso do verbo, e, desta forma, há a produção de uma sentença agramatical em inglês. ${ }^{12}$

Semelhantemente à existência de objeto pro nas línguas, a existência ou não de sujeito pro, de acordo com Nespor e Guasti (2001), também desencadeia a opção escolhida pelas línguas na satisfação do princípio FSA.

A sentença (11) em italiano dada pelas autoras, com a proeminência principal no último constituinte (fonológico), assinalada por regras de proeminência relativa que se aplicam em sintagmas entoacionais, é adequada tanto em um contexto com foco de escopo estreito em Calvino como em um contexto de foco de escopo largo (no caso, foco em toda a sentença). De fato, a sentença (11) pode ser uma resposta para ambas as indagações em (12).
(11) È morto Calvino.
é - morto - Calvino
'Calvino morreu'.
(12) a. Cosa è successo?
'O que aconteceu?'

12 Segundo Nespor e Guasti (2001), é sabido que, em inglês, NPs (objetos) podem ser encontrados não adjacentes ao verbo quando eles são pesados (Ex.: I gave to John the book that Mary wrote last year.) e quando são contrastivamente focalizados (Ex.: I didn't give a pen to John. I gave to John a book.). Nos casos de NPs pesados, a ordem V PP NP só é pennitida, embora em inglès não haja pronome pro, pois há evidência de que sentenças envolvendo movimento de NPs pesados são derivadas por um movimento em estrutura profunda na qual NP precede PP. A evidência para esta análise vem do fato de que em sentenças em que ocorre movimento de NPs pesados, lacunas parasitas são licenciadas, como acontece quando o movimento $A^{\prime}$ está envolvido. Vejamos o exemplo retirado de Belleti e Shlonsky (1995): 1 crossed $t_{i}$ without $e c_{i}$ recognizing a classmate with whom I attended primary school. Conforme Nespor $e$ Guasti (2001), neste exemplo, a categoria vazia, ec, é uma lacuna parasita licenciada por um elemento nulo à esquerda, $t_{\mathrm{j}}$, por um movimento do NP pesado. As mesmas autoras consideram que em estrutura profunda a ordem de $V$ PP NP é $V t_{i}$ PP NP, no caso de movimento de NPs pesados em inglês, onde $t$ é uma variável receptora de caso. Deste modo. a adjacència requerida na atribuição de caso é satisfeita. 
FERNANDES, F. R. Ordem, estratégias de focalização, preenchimento...

\section{b. Chi è morto?}

'Quem morreu?'

Contrariamente, a ordem das palavras em (13) com Calvino em posição pré-verbal é escolhida em um contexto em que é sabido que Calvino está doente. Neste caso, apenas o predicado é uma informação nova. A sentença (13), de fato, é uma resposta adequada a (14). Dado que a estrutura prosódica é mapeada na superfície da estrutura sintática, também neste caso, a proeminência principal no sintagma entoacional é à direita.

(13) Calvino è morto.

Calvino - é - morto

'Calvino morreu.'

(14) Cosa è successo a Calvino?

'O que aconteceu com Calvino?'

Dado que ambas as ordens em (11) e em (13) são permitidas em italiano, o movimento da proeminência não é uma opção permitida nesta língua, como pode ser visto pela agramaticalidade das sentenças (15a) e (15b) dadas por Nespor e Guasti (2001), em resposta a (14) e (12b) respectivamente:

\section{(15) a. * È morto Calvino. \\ b. * Calvino è morto.}

Segundo Nespor e Guasti (2001), a ordem das palavras em (11)é permitida uma vez que o italiano é uma língua pro-drop, i. e., o italiano é uma língua que permite sentenças com sujeitos foneticamente não realizados e sentenças com sujeito pós-verbal (Rizzi, 1982). Já o inglês como não é uma língua pro-drop, não permite sujeitos pós-verbais, como Nespor e Guasti (2001) mostram a partir da agramaticalidade do exemplo (16), correspondente ao exemplo (11) em italiano.

(16) *Died Calvino.

'Morreu Calvino.'

Em inglês, ainda conforme as mesmas autoras, apenas a ordem das palavras em (17) é possível. Com a proeminência principal assinalada na fronteira direita do sintagma entoacional, a sentença (17) pode ser uma resposta às questões em (18). 
(17) Calvino died. 'Calvino morreu.'

(18) a. What happened?

'O que aconteceu?'

b. What happened to Calvino?

'O que aconteceu com o Calvino?'

Dado que nenhuma outra ordem é possível, a pergunta em (19), que diz respeito à identidade da pessoa que morreu, pode ser respondida em inglês apenas com uma sentença em que a proeminência principal foi mudada para $o$ sujeito, como indicado em (20). Esta sentença, em geral, pode ser usada em um contexto em que a morte de Calvino é inesperada.

(19) Who died?

'Quem morreu?'

(20) Calvino died.

'Calvino morreu.'

O foco estreito no sujeito pode ser obtido, em inglês, apenas pelo movimento da proeminência.

Segundo Nespor e Guasti (2001), estes fatos demonstram mais uma vez que o movimento da proeminência é possível apenas se outras opções sintáticas não estão disponíveis em dada língua.

\section{As opções escolhidas por PE e PB para satisfazer o princípio FSA}

Neste artigo, trataremos apenas dos casos em que o sujeito é o elemento focalizado nas sentenças.

Quando se toma como objeto de análise o PE e o PB, notamos, a partir da observação dos exemplos dados logo abaixo, que PE opta por uma ordem tal dos elementos nas sentenças de maneira que o elemento focalizado e portador de proeminência fonológica principal da sentença, no caso, o Paulo (sujeito), ocupe a posição mais à direita da sentença. Já $\mathrm{PB}$, ao invés de optar pela mudança de 
FERNANDES, F. R. Ordem, estratégias de focalizaçāo, preenchimento...

ordem dos elementos nas sentenças, opta pelo movimento da proeminência principal para $o$ Paulo (sujeito focalizado). Ou seja, PE escolhe a primeira opção apresentada por Nespor e Guasti (2001) para a satisfação do principio FSA, enquanto $\mathrm{PB}$ opta pela segunda opção apresentada pelas mesmas autoras na satisfação do mesmo princípio. Faz-se necessário notar que, no dado de $\mathrm{PB}$, se há mudança dos constituintes sujeito $(\mathrm{S})$, verbo $(\mathrm{V})$ e objeto $(\mathrm{O})$ na sentença de maneira que o elemento focalizado (no caso, o sujeito) ocupe a última posição da sentença e a nova ordem resultante desta mudança seja VOS, isso acarreta agramaticalidade em PB.

(21) Em PE: $:{ }^{13}$ Quem partiu a janela?

Partiu a janela o. Paulo.

*O Paulo partiu a janela.

(22) Em PB: Quem quebrou a janela?

Q Paulo quebrou a janela.

*Quebrou a janela o Paulo.

Dado que tanto PE quanto PB são línguas pro-drop, é possível pensarmos que a escolha de opções diferentes realizadas por essas duas variedades de Português na satisfação do princípio FSA não esteja unicamente relacionada à fixação do parâmetro \pm pro, como afirmam Nespor e Guasti (2001), mas também a questões de outra natureza.

\section{Corpora e metodologia}

Em nosso trabalho utilizaram-se dois corpora de fala providos do mesmo conteúdo informacional em ambas as variedades de Português. O primeiro corpus é constituído por leituras de textos bíblicos em duas missas católicas, uma em Portugal e a outra no Brasil, ambas transmitidas no mesmo dia via televisão (TVE / Rio e RTP / Lisboa). O segundo corpus é composto por trechos de fala do filme A Dama e o Vagabundo, traduzido do inglês para PB e PE.

Destes textos foi selecionado um conjunto de enunciados que possuíam o mesmo constituinte sujeito focalizado, mas apresentavam uma ordem diferente dos elementos nas sentenças de PB e PE. Posteriormente, foram transcritos os

13 Os dados de PE foram extraídos de Costa (1998). 
FERNANDES, F. R. Ordem, estratégias de focalização, preenchimento...

eventos tonais dos contornos entoacionais destas sentenças, bem como foram marcadas as fronteiras dos sintagmas entoacionais (I), conforme o algoritmo de Nespor e Vogel (1986). ${ }^{14}$ A transcrição dos eventos tonais foi realizada com a utilização do programa computacional de análise de fala Praat (http:// www.fon.hum.uva.nl/praat) e baseada em Pierrehumbert (1980) e Pierrehumbert e Beckman (1988).

\section{Apresentação de dados e discussão}

Os dados apresentados logo abaixo ilustram bem o paradigma que ocorre na totalidade de nossos dados envolvendo sujeito focalizado em sentenças de PE e PB de nossos corpora e corroboram a afirmação de que PE e PB tendem a satisfazer o princípio FSA diferentemente. ${ }^{15}$

Os exemplos (23) e (24) mostram que em PE há mudança de ordem dos constituintes nas sentenças de forma que o elemento focalizado - o sujeito 'cães' em (23) e o sujeito 'eu' em (24) - ocupe a posição mais próxima à fronteira direita do sintagma entoacional (posição pós-verbal e final da sentença). ${ }^{16}$ Por sua vez, em $\mathrm{PB}$, não há mudança de ordem dos elementos das sentenças e a proeminência fonológica principal destas é movida para o elemento focalizado que ocupa a posição pré-verbal e mais próxima à fronteira esquerda do sintagma entoacional (início das sentenças). ${ }^{17}$

14 De acordo com Nespor e Vogel (1986, p. 189), eis a algoritmo de formação de sintagma entoacional (I):

Intonational Phrase formation

I. An I domain may consist of

a. all the fs in a string that is not structurally attached to the sentence tree at the level of s-structure,

or

b. any remaining sequence of adjacent fs in a root sentence.

II. I construction

Join into an $n$-ary branching I all fs included in a string delimited by the definition of the domain

of 1 .

Essas mesmas autoras ainda afirmam que a formação básica de l é baseada na noção de que as fronteiras finais de sintagmas entoacionais coincidem com posiçðes em que pausas podem ser introduzidas em uma sentença (Nespor; Vogel. 1986, p. 188).

15 Nesta seção 4 do presente artigo utilizamos, como exemplos, apenas enunciados extraídos de um de nossos corpora (corpus do filme A Dama e o Vagabundo, traduzido para PE e PB respectivamente).

16 Neste trabalho considera-se que a ordem neutra de sentenças em PB. do ponto de vista informacional, e SVO e considera-se juntamente com Costa (1998) que a ordem neutra de sentenças em PE, do ponto de vista informacional, também é SVO.

17 Essa observação corrobora as afirmações de Kato e Raposo (1996) sobre foco inicial em PB. 
FERNANDES, F. R. Ordem, estratégias de focalizaçāo, preenchimento...

(23) Em PE: [Não são permitidos cães $]_{1}^{18}$

Em PB: [Cães não são permitidos]

(24) Em PE: ... é alguma coisa que eu fiz. [Acho $\underline{\mathrm{eu}}_{1}$

Em PB: ... foi uma coisa que eu fiz. [Eu acho],

Com base na observação das figuras destaca-se que os constituintes focalizados nas sentenças de PB - os sujeitos 'cães' em (23) e 'eu' em (24) aparecem na fronteira esquerda e inicial do sintagma entoacional e portam a proeminência principal da sentença, já os mesmos elementos focalizados nos enunciados de PE nem sempre carregam a proeminência principal da sentença. No enunciado (23) de PE o elemento focalizado 'cães' carrega a proeminência fonológica principal da sentença, porém no enunciado (24), é o elemento inicial da sentença 'acho' que carrega a proeminência fonológica principal da sentença e não o elemento focalizado ' $e u$ '.

Nossos exemplos corroboram a afirmação feita na seção 2 deste artigo de que PE parece escolher a primeira opção apresentada por Nespor e Guasti (2001) para satisfazer o princípio FSA e PB parece escolher a segunda opção apresentada pelas mesmas autoras para satisfação do mesmo princípio. Nossos dados também nos permitem conjeturar que, dado que tanto $P E$ quanto $P B$ são línguas pro-drop, a escolha de opções diferentes realizadas pelas línguas na satisfação do princípio FSA não esteja unicamente relacionada à fixação do parâmetro \pm pro, como afirmam Nespor e Guasti (2001), mas também a questões de outra natureza.

18 Nestes exemplos, as fronteiras de sintagmas entoacionais (Is) são delimitadas por colchetes "[l]". os elementos sublinhados são os elementos focalizados e os elementos em negrito são os elementos portadores de proeminência fonologica principal nas sentenças. Considera-se aqui que os elementos portadores de proeminência fonológica principal das sentenças são aqueles que são percebidos auditivamente como mais proeminentes e que apresentam um evento tonal $\mathrm{H}$ saliente em relação aos outros eventos tonais $\mathrm{H}$ que aparecem nas mesmas sentenças. 
FIGURA 1

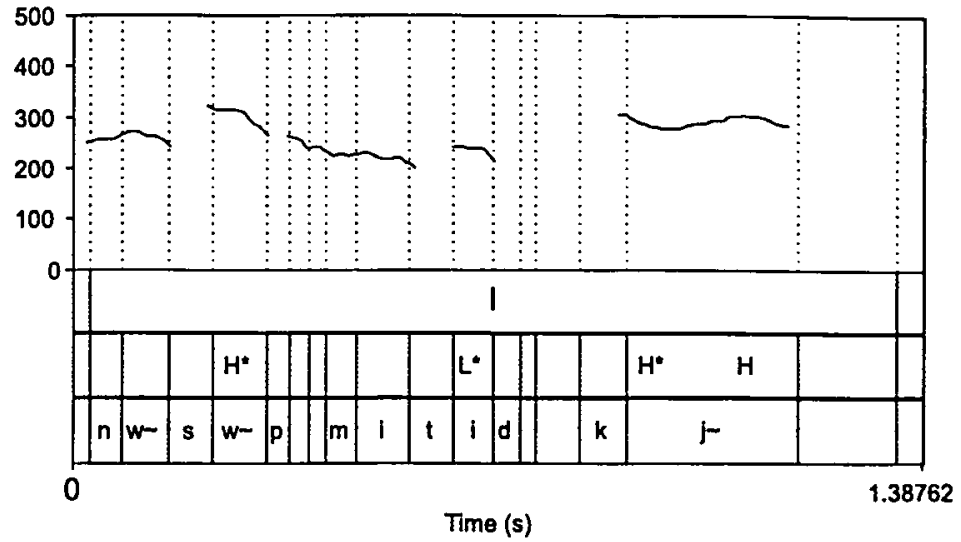

Figura correspondente à curva entoacional do enunciado (23) de PE. Na figura: (i) o eixo da abscissa marca a variaçāo do tempo em segundos e o eixo da ordenada marca a variação da curva entoacional em hertz; (ii) a primeira linha de baixo para cima é destinada à transcrição fonética; (iii) a segunda linha é destinada à transcrição dos eventos tonais e; (iv) por sua vez, a terceira linha de baixo para cima é destinada à delimitação das fronteiras do sintagma entoacional.

FIGURA 2

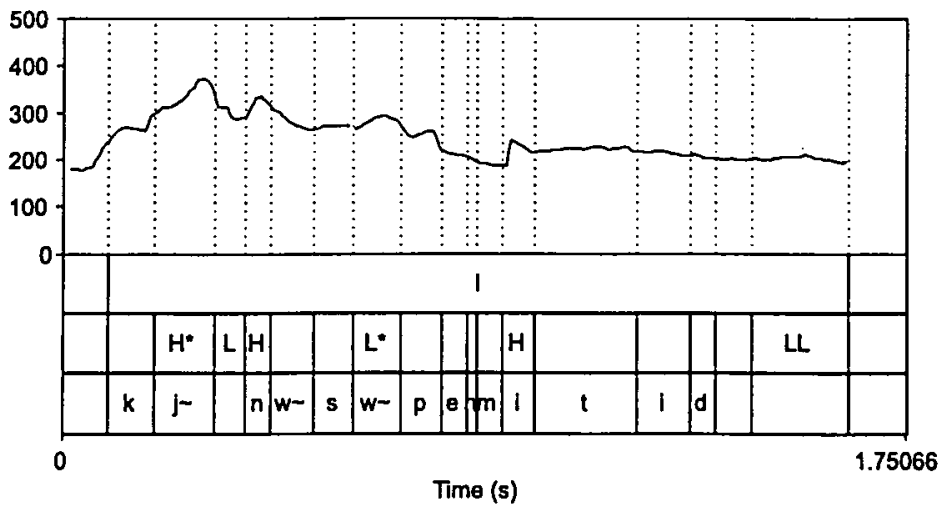

Figura correspondente à curva entoacional do enunciado (23) de PB. Na figura: (i) o eixo da abscissa marca a variação do tempo em segundos e o eixo da ordenada marca a variação da curva entoacional em hertz; (ii) a primeira linha de baixo para cima é destinada à transcrição fonética; (iii) a segunda linha é destinada à transcrição dos eventos tonais e; (iv) por sua vez, a terceira linha de baixo para cima é destinada à delimitaçāo das fronteiras do sintagma entoacional. 
FERNANDES, F. R. Ordem, estratégias de focalizaçāo, preenchimento...

FIGURA 3

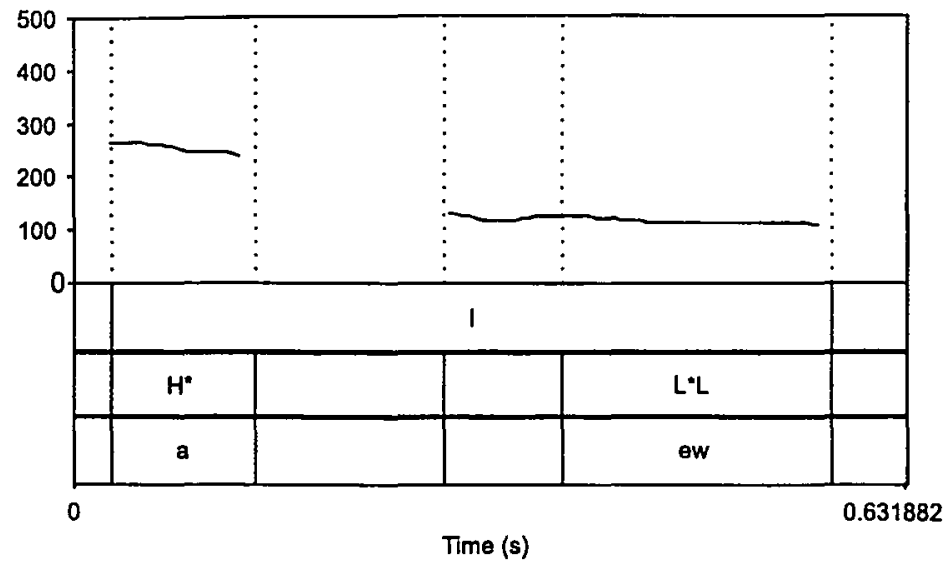

Figura correspondente à curva entoacional do enunciado de (24) PE. Na figura: (i) o eixo da abscissa marca a variação do tempo em segundos e o eixo da ordenada marca a variação da curva entoacional em hertz; (ii) a primeira linha de baixo para cima é destinada à transcrição fonética; (iii) a segunda linha é destinada à transcrição dos eventos tonais e; (iv) por sua vez, a terceira linha de baixo para cima é destinada à delimitação das fronteiras do sintagma entoacional.

FIGURA 4

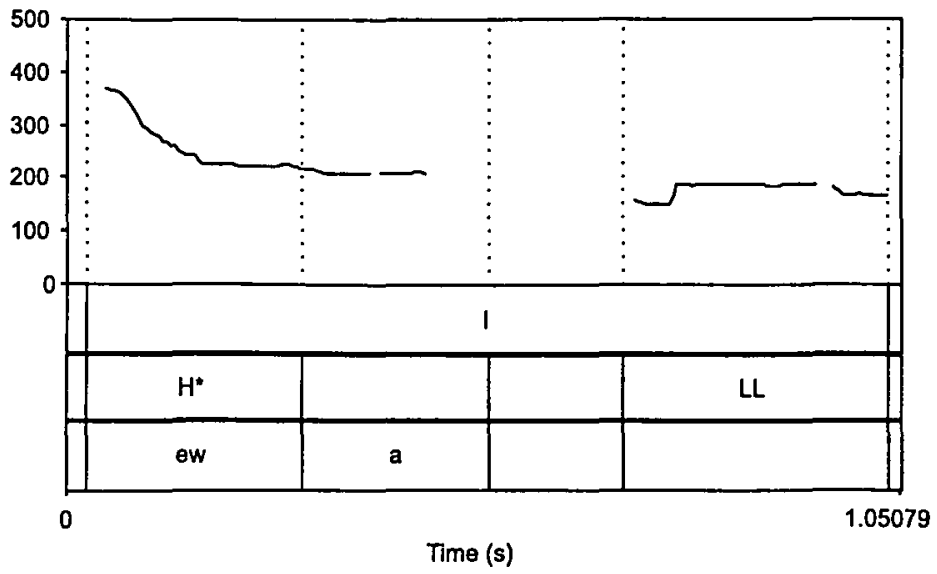

Figura correspondente à curva entoacional do enunciado (24) de PB. Na figura: (i) o eixo da abscissa marca a variaçāo do tempo em segundos e o eixo da ordenada marca a variação da curva entoacional em hertz; (ii) a primeira linha de baixo para cima é destinada à transcrição fonética; (iii) a segunda linha é destinada à transcrição dos eventos tonais e; (iv) por sua vez, a terceira linha de baixo para cima é destinada à delimitação das fronteiras do sintagma entoacional. 
FERNANDES, F. R. Ordem, estratégias de focalizaçāo, preenchimento...

Cabe notar que tanto $\mathrm{PB}$ quanto $\mathrm{PE}$ são línguas de sujeito nulo, porém, é sabido que o sujeito nulo em PE e o sujeito nulo em PB são objetos de diferentes naturezas e propriedades (sobre sujeito nulo em PB, ver, dentre outros, Duarte, 1995; Figueiredo Silva, 1996; Ferreira, 2000; Kato; Negrão, 2000). Apesar de que, com base na redução de ocorrência de sujeitos nulos nas sentenças e as restrições sobre ele operando, se possa afirmar que o PB deixou de ser uma língua prodrop, faz-se necessário notar que o PB não pode ser considerado uma língua típica de sujeito não-nulo como o inglês ou o francês. Sentenças, contendo verbos como 'chover', que apresentam a posição do sujeito preenchida lexicalmente em francês ( $l l$ pleut), ou em inglês (It rains), seriam agramaticais, se fosse seguido o mesmo paradigma de preenchimento lexical da posição do sujeito, na tradução para PB (*Ele chove). Dadas estas considerações, é plausível considerar, juntamente com Galves (2001), que PB é uma língua de sujeito nulo por se adequar aos critérios definidos por Chomsky (1981) para essas línguas.

Nossa hipótese é de que as estratégias de focalização escolhidas pelas línguas também estejam relacionadas a questōes de natureza rítmica, entoacional e prosódica.

As características rítmicas, entoacionais e prosódicas de $\mathrm{PB}$ e PE têm sido objeto de análise de muitos autores, dentre eles Abaurre, Galves e Scarpa (1999), Abaurre et al. (2001), Barbosa (1995; 1996; 2002a; 2002b; 2002c), Frota (1998), Frota e Vigário (2000), Vigário (2001), Tenani (2002), Duarte et al. (2001).

Com base em alguns dos trabalhos anteriormente mencionados, pode-se destacar, quanto às diferenças rítmicas, entoacionais e prosódicas entre PB e PE, que: (i) conforme Frota e Vigário (2000) e Duarte et al. (2001), baseados no trabalho de Ramus, Nespor e Mehler (1999), PB e PE pertencem a classes rítmicas diferentes, no sentido de Pike (1945) e Abercrombie (1967); (ii) segundo Abaurre et al. (2001) e Frota e Vigário (2000), a atribuição de acentos rítmicos é muito mais binária em PB do que em PE; (iii) de acordo com Tenani (2002) para o PB e Vigário (2001) para o PE, a palavra prosódica em PE é o principal domínio na aplicação de processos rítmicos, enquanto em $\mathrm{PB}$ é o sintagma fonológico o principal domínio na aplicação de processos ritmicos; e (iv) segundo Frota (1998) e Frota e Vigário (2000), em PB, o domínio relevante para a atribuição de eventos tonais é o sintagma fonológico enquanto em $\mathrm{PE}$ é o sintagma entoacional, que é marcado com um evento tonal associado ao acento nuclear de I, e um evento tonal inicial. Os exemplos aqui apresentados corroboram, em especial, a afirmação apresentada em (iv) na medida em que nos enunciados (23) e (24) de PE há sempre um evento tonal inicial (em (23) há um evento tonal inicial $\mathrm{H}$ em 'são' e em (24) há um evento tonal inicial H em 'acho') e os eventos tonais no enunciado (23) de PB ocorrem 
FERNANDES, F. R. Ordem, estratégias de focalização, preenchimento...

no domínio do sintagma fonológico (f), ${ }^{19}$ enquanto os eventos tonais no enunciado (24) de PE ocorrem no domínio do sintagma entoacional (I):

PB: [Cães] [não são] [permitidos] $_{\mathfrak{f}}$ $\begin{array}{lllll}\mathrm{H}^{*} \mathrm{~L} & \mathrm{H} & \mathrm{L}^{*} & \mathrm{H} & \mathrm{LL} \%\end{array}$

PE: [Não são permitidos cães] $\mathrm{H}^{*} \quad \mathrm{~L}^{*} \mathrm{H} \mathrm{H}^{*} \%$

Essa disposição dos eventos tonais nas duas variedades de português pode explicar a escolha por estratégias de focalização diferentes. Como sugerido por Abaurre [c.p.], uma vez que o início do sintagma entoacional em PE já é proeminente, não há como marcar focalização por proeminência fonológica nessa posição (ver figuras correspondentes aos enunciados 23 e 24 de PE para constatação do exposto). $\mathrm{O} \mathrm{PB}$, ao contrário, não dispõe necessariamente de uma proeminência inicial de sintagma entoacional e, além disso, apresenta eventos tonais associados a cada sintagma fonológico, o que permite uma marcação de proeminência fonológica in situ no sintagma fonológico que contém o elemento focalizado.

\section{Considerações finais}

Neste artigo foram apresentadas as opções escolhidas pelas linguas para satisfazer o princípio FSA de Jackendoff, conforme Nespor e Guasti (2001), e as escolhas realizadas por PB e PE para satisfazer o mesmo princípio.

As escolhas diferentes realizadas por PB e PE para satisfazer o princípio FSA parecem revelar que as escolhas realizadas pelas línguas para satisfazer tal $(\mathrm{f} \phi):$

19 Conforme Nespor e Vogel (1986, p. 168), eis o algoritmo de formação de sintagma fonológico

Formação de Sintagma Fonológico

1. o domínio de $\mathrm{f} \phi$

$O$ dominio de $f$ consiste em um $C$ (grupo clítico) que contenha uma cabeça lexical $(X)$ e todos os $\mathrm{Cs}$ do lado não recursivo até o $\mathrm{C}$ que contenha outra cabeça fora da projeção máxima de $\mathrm{X}$.

II. construção

Acrescente em um $\mathrm{f}$ de ramificaçāo $n$-ária todos os $\mathrm{Cs}$ incluídos em uma cadeia delimitada pela definição do domínio de $f \phi$. 
FERNANDES, F. R. Ordem, estratégias de focalização, preenchimento...

princípio não estão apenas relacionadas com a fixação do pronome \pm pro, mas também a questões de outra natureza, como questões rítmicas. A investigação destes fenômenos lingüísticos mostra que parece haver uma complexa relação entre ritmo, preenchimento lexical das posições de sujeito e estratégias de focalização nas línguas.

Cabe acrescentar que o presente trabalho consiste em um trabalho preliminar, mais sugestivo do que conclusivo, que essencialmente aponta uma possível relação nas línguas entre ritmo, estratégias de focalização e preenchimento lexical da posição do sujeito. A investigação desta relação, bem como a investigaçăo das estratégias de focalização utilizadas por PB e PE, deverão ser realizadas de maneira mais aprofundada em etapas posteriores da pesquisa.

\section{RESUMO}

Este artigo trata da relação, em PB e em PE, entre a ordem de palavras, 0 preenchimento lexical da posição do sujeito e as diferentes estratégias de focalização escolhidas por essas duas variedades de português na satisfação do princípio FSA de Jackendoff (1972). Segundo Nespor e Guasti (2001), as línguas teriam duas op̧̧ões para satisfazer esse princípio: 1. uma ordem diferente dos elementos na sentença é escolhida de tal forma que o elemento focalizado esteja mais à direita no sintagma entoacional; 2 . a proeminência principal é movida para o constituinte marcado $[+\mathrm{F}]$ na árvore sintática. Conforme as mesmas autoras, línguas como o inglês optariam por 2, enquanto línguas como o italiano optariam por 1 . Nespor e Guasti (2001) afirmam que os mecanismos diferentes utilizados em inglês e em italiano para o alinhamento foco-proeminência são a conseqüência de fixações diferentes de um parâmetro sintático específico $( \pm$ pro). Ou seja, línguas pro-drop optariam por 1 na satisfação do princípio FSA, enquanto línguas não pro-drop optariam por 2. Quando se tomam como objetos o PE e o PB, nota-se, a partir da análise de dados, que enquanto $P E$ opta por 1 na satisfação do princípio FSA, PB opta por 2. Dado que tanto PE quanto PB são línguas pro-drop, a hipótese apresentada neste artigo é a de que as diferentes opções escolhidas pelas línguas para satisfazer o princípio FSA estejam relacionadas não só à fixação do valor do parâmetro \pm pro, mas também a questões de outra natureza, como, por exemplo, questões rítmicas.

Palavras-chave: focalização, ritmo, sujeito nulo. 
FERNANDES, F. R. Ordem. estratégias de focalização, preenchimento...

\section{ABSTRACT}

This paper addresses the relationship, in EP and BP, between word order, lexical filling of the subject position and the different options chosen by these two varieties of Portuguese to satisfy the Jackendoff's principle Focus to Stress Alignment (FSA). Nespor and Guasti (2001) assert that languages may have two options to satisfy this principle: 1) a different order of the constituents in the sentence is chosen in such a way that the focused element be at right in the intonational phrase; 2) the main prominence is moved to the constituent marked $[+F]$ in the syntactic tree. According to the same authors, languages such as English would choose number 2), whereas languages such as Italian would choose number 1). Nespor and Guasti (2001) affirm that different mechanisms used in English and in Italian for focus-prominence alignment are consequence of the different settings of a specific syntactical parameter ( \pm pro). Pro-drop languages would choose number 1) to satisfy FSA principle, whereas no pro-drop languages would choose number 2). When we analyze European Portuguese (EP) and Brazilian Portuguese (BP), we observed (through our analyzed data) that EP chooses number 1) to satisfy FSA principle and BP chooses number 2). The linguistic literature shows that both EP and BP are pro-drop languages, so the hypothesis presented in this paper is that the different options chosen by languages to satisfy Jackendoff' $s$ principle are related not only to the value setting of \pm pro parameter, but also to questions of other nature, such as rhythmic questions.

Key-words: focus, rhythm, null subject.

\section{REFERÊNCIAS}

ABAURRE, Maria Bernadete; GALVES, Charlotte; SCARPA, Ester. A interface fonologia/ sintaxe. Evidências do português brasileiro para uma hipótese top-down na aquisição da linguagem. In: SCARPA, E. (Org.). Estudos de Prosódia no Brasil. Campinas: Unicamp, 1999.

et al. The sotaq optimality based computer program and secondary stress in two varieties of Portuguese. Rutgers Otimality Arquive, 463-0801, 2001.

ABERCROMBIE, D. Elements of general phonetics. Chicago: Aldine, 1967.

BARBOSA, Plínio. Estrutura rítmica da frase revelada por aspectos de produçāo e percepção de fala. In: SEMINÁRIO DO GEL, 43., 1995, São Paulo.

Explaining Brazilian Portuguese resistance to stress shift with a coupled-oscillator model of speech rhythm production. Cadernos de Estudos Lingüisticos, v. 43, p. 71-92, $2002 a$. 
FERNANDES, F. R. Ordem, estratégias de focalização, preenchimento...

- Integrating gestural temporal constraints in a model of speech rhythm production. In: HAWKINS, S.; NGUYEN, N. (Eds.). Temporal integration in the perception of speech. 2002b. p. 54.

Explaining cross-linguistic rhythmic variability via a coupled-oscillator model of Rhythm Production. In: BEL, B.; MARLIEN, I. (Eds.). Proceedings of the speech prosody 2002 conference, 11-13 April. Aix-en-Provence: Laboratoire Parole et Langage, 2002c. p. 163-166.

BELLETTI, Adrianar; SHLONSKY, Ur. The order of verbal complements: a comparative study. Natural Language and Linguistic Theory, v. 13, p. 489-526, 1995.

CHOMSKY, Noam; HALLE, Morris. The sound pattern of English. New York: Harper and Row, 1968.

CHOMSKY, Noam. Deep structure, surface structure and semantic interpretation. In: STEINBERG, D.; JAKOBOVITS, L. (Eds.). Semantics: an interdisciplinary reader in philosophy, linguistics and psychology. Cambridge, UK: Cambridge University Press, 1971.

Lectures on government and binding. Dordrecht: Foris, 1981.

Knowledge of language, Its nature origin and use. New York: Praeger, 1985.

COSTA, João. Word order variation. A constaint-based approach. Netherlands: Holland Academic Graphics, 1998.

DUARTE, Maria Eugenia. A perda do principio "Evite pronome" no português brasileiro. Campinas, 1995. Tese (Doutorado) - Universidade Estadual de Campinas.

DUARTE, Denise et al. The statistical analysis of acoustic correlates of speech rhythm. In: WORKSHOP RHYTHMIC PATTERNS, PARAMETER SETTING AND LANGUAGE CHANGE, 2001, Alemanha. Anais... Alemanha: ZiF, University of Bielefeld, 2001.

FERREIRA, Marcelo. Argumentos nulos em português. Campinas, 2000. Dissertação (Mestrado) - Instituto de Estudos da Linguagem da Universidade Estadual de Campinas.

FIGUEIREDO SILVA, Maria Cristina. A posição sujeito no português brasileiro: frases finitas e infinitivas. Campinas: Unicamp, 1996.

FROTA, Sónia. Prosody and focus in European Portuguese. Lisboa, 1998. Dissertação (Mestrado) - Faculdade de Letras da Universidade de Lisboa, 1998.

; VIGÁRIO, Marina. Aspectos de prosódia comparada: ritmo e entoação no PE e no PB. Braga: Universidade de Lisboa e Universidade do Minho, 2000.

GALVES, Charlotte. A gramática do português brasileiro. Linguas e instrumentos linguiísticos, $n^{\circ}$ 1. Pontes, 1998.

Ensaios sobre as gramáticas do português. Campinas: Ed. da Unicamp, 2001.

JACKENDOFF, Ray. Semantic interpretation in generative grammar. Cambridge: MIT Press, 1972.

KATO, Mary; NEgRÃO, Esmeralda. (Eds.). Brazilian Portuguese and the Null Subject Parameter. Madrid: Iberoamericana, 2000. 
FERNANDES, F. R. Ordem, estratégias de focalização, preenchimento...

; RAPOSO, Eduardo. European and Brazilian word order: questions, focus and topic constructions. In: PARODI, C. et al. (Eds.). Aspects of romance linguistics. Washington: Georgetown, U. Press, 1996. p. 267-277.

NEELEMAN, Ad; REINHART, Tanya. Scrambling and the PF interface. In: GUEDER, W; BUTT, M. (Eds.). Projecting from the Lexicon. CSLI. Stanford, 1998.

NESPOR, Marina; VOGEL, Irene. Prosodic phonology. Dordrecht: Foris Publications, 1986. ; GUASTI, Maria Teresa. Focus to stress alignment, submitted, 2001.

PIERREHUMBERT, Janet. The phonology and phonetics of English intonation. Cambridge, 1980. Ph.D. (Dissertation) - M.I.T.

; BECKMAN, Mary. Japanese tone structure. Cambridge, Mass.: M.I.T. Press, 1988.

PIKE, Kenneth. The intonation of American English. Ann Arbor, Michigan: University of Michigan Press, 1945.

RAMUS, Franck; NESPOR, Marina; MEHLER, Jacques. Correlates of linguistic thythm in the speech signal. Cognition, n. 73, p. 265-292, 1999.

RAPOSO, Eduardo. On the null object in European Portuguese. In: JAEGGLI, O.; SILVACORVALAN, C. (Orgs.). Studies in romance linguistics. Dordrecht: Foris, 1986.

RIZZI, Luigi. Issues in Italian syntax. Dordrecht: Foris, 1982.

STOWELL, Timothy. Origins of Phrase Structure. Massachusetts, 1981. Doctoral Dissertation - Massachusetts Institute of Technology.

TENANI, Luciani. Dominios prosódicos no português. Campinas, 2002. Tese (Doutorado) - Instituto de Estudos da Linguagem da Universidade Estadual de Campinas.

VIGÁRIO, Marina. The prosodic word in European Portuguese. Lisboa, 2001. Tese (Doutorado) - Faculdade de Letras da Universidade de Lisboa.

ZUBizarReta, Maria Luiza. Prosody, focus and word order. Cambridge, Mass: M.I.T. Press, 1998. 